\title{
Enterocutaneous Fistula Formation of Meckel's Diverticulum via the Urachal Cyst in an Adult Patient: A Case Report and Literature Review
}

\author{
S. Hatipoglu ${ }^{1}$, R. Abdullayev ${ }^{2}$, C. Benlioglu ${ }^{3}$, M. Goksu $^{1}$, F. Hatipoglu ${ }^{4}$ \\ and E. Bayramoglu ${ }^{1}$ \\ ${ }^{1}$ Department of General Surgery Unit, School of Medicine, Adiyaman University, Adiyaman, Turkey \\ ${ }^{2}$ Department of Anesthesiology and Reanimation Unit, School of Medicine, Adiyaman University, \\ Adiyaman, Turkey \\ ${ }^{3}$ Department of Urology Unit, School of Medicine, Adiyaman University, Adiyaman, Turkey \\ ${ }^{4}$ Department of Obstetrics and Gynecology Unit, School of Medicine, Adiyaman University, \\ Adiyaman, Turkey
}

Correspondence should be addressed to: S. Hatipoglu; hamitsinanh@gmail.com

Received Date: 28 October 2013; Accepted Date: 10 December 2013; Published Date: 1 March 2014

Academic Editor: Rifat Latifi

Copyright (C) 2014 S. Hatipoglu, R. Abdullayev, C. Benlioglu, M. Goksu, F. Hatipoglu and

E. Bayramoglu. Distributed under Creative Commons CC-BY 3.0

\begin{abstract}
Meckel's diverticulum (MD) is the most common congenital anomaly of small intestine. It is the most common end result of the spectrum of omphalomesenteric duct anomalies, which also include umbilicoileal fistula, umbilical sinus or cyst, and a fibrous cord connecting the ileum to the umbilicus. Besides this, abnormal remnants of the urachus can present as patent urachus, vesicourachal diverticulum, urachal sinus or urachal cyst (UC). Urachal cysts represent an incomplete closure of the urachus, a cord-like structure connecting the primitive bladder to the umbilicus in early embryonic formation.
\end{abstract}

Primary aim of this study was to present and share an orginal case of enterocutaneous fistula formation of MD via the UC in an adult patient, which is the first in literature.

A 39-year-old male applied to the emergency surgery service with complaints of increasing abdominal pain, nausea, vomiting and fecal discharge from the umbilicus. Laparotomy was carried out with a suspicion of intrabdominal mass and enterocutaneous fistula formation. The surgical exploration revealed enterocutaneous fistula formation of MD via the UC. The patient was treated successfully with resection of UC and MD, and had an uneventful postoperative recovery. We conducted a literature review of studies published in the English language on

Cite this Article as: S. Hatipoglu, R. Abdullayev, C. Benlioglu, M. Goksu, F. Hatipoglu and E. Bayramoglu (2014), "Enterocutaneous Fistula Formation of Meckel's Diverticulum via the Urachal Cyst in an Adult Patient: A Case Report and Literature Review," International Journal of Case Reports in Medicine, Vol. 2014 (2014), Article ID 419399, DOI: 10.5171/2014.419399 
Meckel's diverticulum and Urachal anomalies, accessed via PubMed, Medline, and the Google Scholar databases.

Urachal enterocutaneous fistula through the umblicus in adult has not been encountered in the literature to the best of our knowledge. We present a original case and literature review.

Keywords: Meckel's diverticulum, urachal cyst, enterocutaneous fistula, adult patient.

\section{Introduction}

Meckel's diverticulum (MD), which is a remnant of the omphalomesenteric duct or vitelline duct, is the most common congenital abnormality of the alimentary tract. Meckel's diverticulum occurs in 0.4 $4 \%$ of the population (but only $5 \%$ of people with it encounter problems) and are found two times more frequently in males compared with females (1-8). The total lifetime complication (intestinal hemorrhage, intestinal obstruction, inflammation and rarely tumoural formation) incidence is $4-5 \%$ and are usually seen in childhood (9-14).

Urachal cysts (UC) are quite rare and most are presented in early childhood. Urachal cysts may develop from a congenital anomaly in which a persistent or partial reopening of the fetal communication between the bladder and the umbilicus persists and many case reports are present in the literature. Residual urachus occurs as a cystic formation, a sinus or a fistulization and may degenerate into adenocarcinoma of severe prognosis (15). Because of variable presentation, the diagnosis of an urachal anomaly can be difficult. Urachal cysts are usually detected in infancy and childhood, rarely seen in adults.

MD and UC have the same embryological origin, which is the yolk sac at the eighth day of life (15). Their developmental processes are independent but the underlying mechanisms are uniform $(1,2$, 15). The presence of these two congenital anomalies together is a very rare pathology and urachal enterocutaneous fistula because of perforated and penetrated MD in an adult derived from an urachal cyst has not been manifested in the previous literature. We present a case of an urachal enterocutaneous fistula derived from UC, because of perforated and penetrated MD in an adult patient. This is the first case in literature, as far as we know.

\section{Methods}

We conducted a literature review of studies published in the English language on Meckel's diverticulum and Urachal anomalies accessed via PubMed, Medline and the Google Scholar databases.

\section{Case Presentation}

A 39-year-old male applied to the emergency surgery service with complaints of increasing abdominal pain, nausea, vomiting and fecal discharge from the umbilicus. The past medical history revealed that the symptoms had begun a month ago. No other remarkable findings like history of gastrointestinal and urinary tract infections, previous hospitalization for the similar symptoms, family history were present.

The patient was $80 \mathrm{~kg}$ in weight, $175 \mathrm{~cm}$ in height. Axillary body temperature was 37.6 ${ }^{\circ} \mathrm{C}$, blood pressure: $145 / 70 \mathrm{mmHg}$, heart rate: 80 beats per minute, respiratory rate: 22 per minute. Physical examination revealed common sensation, defensive and rebound tenderness in the abdomen. Bowel sounds were normoactive. A local tenderness, hyperemia, malodorous intestinal secretion, superficial bruising, a palpable mass and fluctuance were noted in the periumblical area. Leucocyte count was $9.740 \mathrm{~mm}^{3}$, hematocrit was $41.5 \%$. Stool microscopy, urine microscopy and urine culture examinations were normal. Abdominal roentgenography showed nonspecific findings. Abdominal ultrasonography (USG) and computed tomography (CT) examinations revealed diffuse thickening of intestinal segment wall from umblicus to pelvic region level 
with inflammatory findings in the neigbour mesenteric fatty plans and an enterocutaneous fistula in the umbilicus. Radiological findings suggested possible complicated Chron's disease, intraabdominal mass or enterocutaneous fistula (Figure 1, 2).

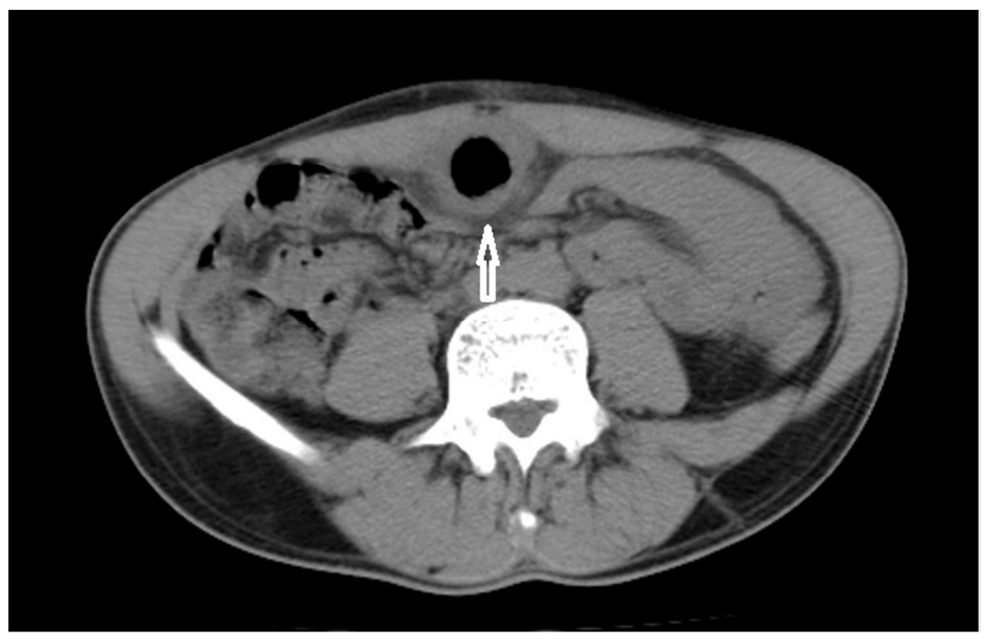

Figure 1. View of Urachal Cyst (White Arrow) in Abdominal Computerized Tomography

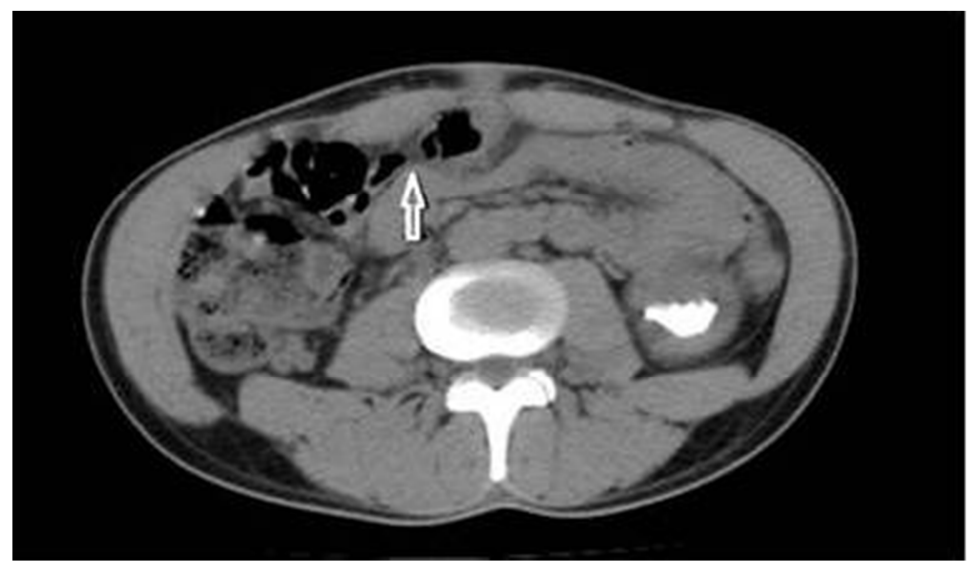

Figure 2. View of Meckel's Diverticulum Junction Urachal Cyst (White Arrow) in Abdominal Computerized Tomography

Laparotomy was carried out with a suspicion of complicated Crohn's disease, intrabdominal mass and enterocutaneous fistula formation. The abdomen was entered with partial upper and lower umbilical incisions to confirm the pathology. During further exploration it was found that the MD was entered and it was perforated into the UC (Figure 3). The reason we thought of it as MD was that, it was originated from the mesenteric side of ileum $80 \mathrm{~cm}$ proximal to the ileocecal valve. Intestinal contents were observed in the UC and throughout the umblicus. The patient underwent Meckel's diverticulectomy with sparing of adjacent bowel, resection of UC and umblical enterocutaneous fistula tract. The UC formation lying between the umbilicus and bladder was excised and ligated toward the bladder side. The resected specimen is presented in Figure 4. A drain was placed in the right paracolic space. No complication occurred during the postoperative follow-up period. The patient was discharged on the sixth postoperative day. 


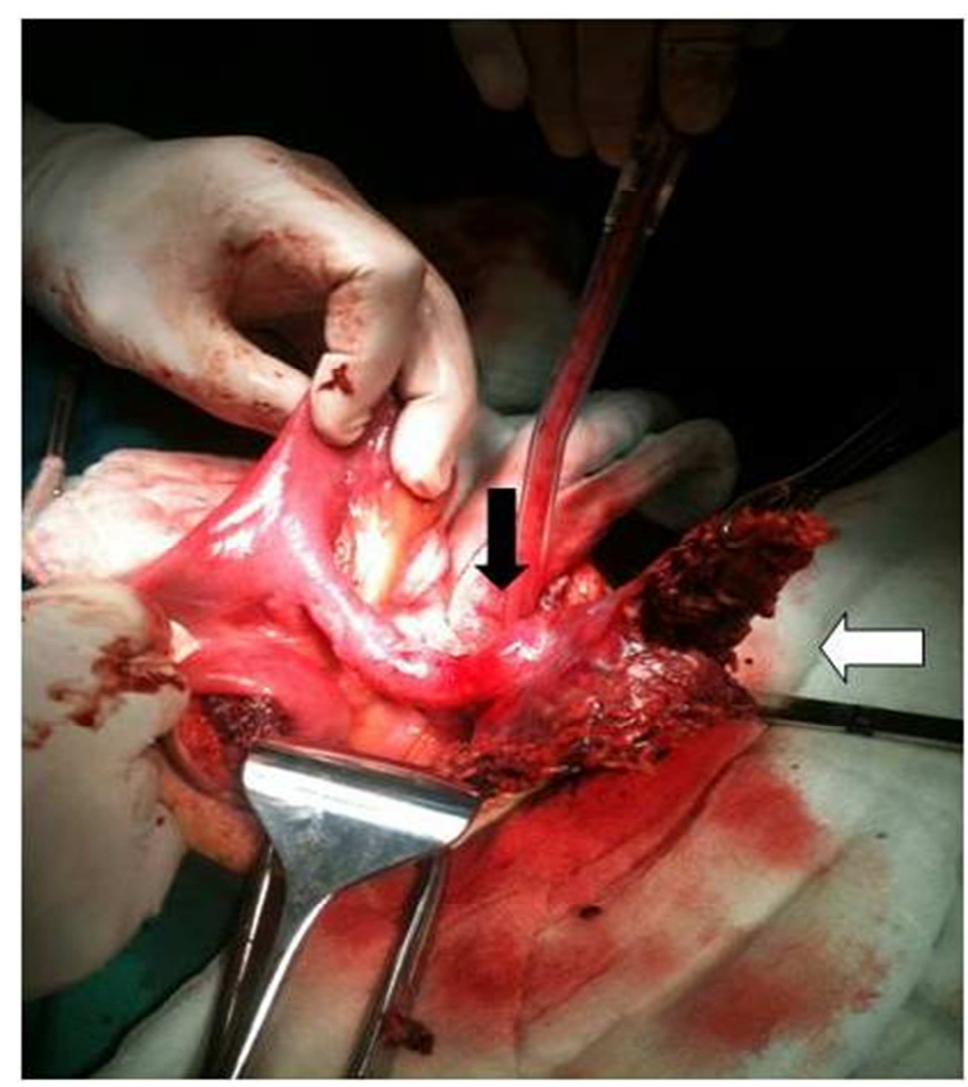

Figure 3. Peroperative View of Meckel's Diverticulum (Black Arrow) Penetrated and Perforated into the Urachal Cyst (White Arrow)

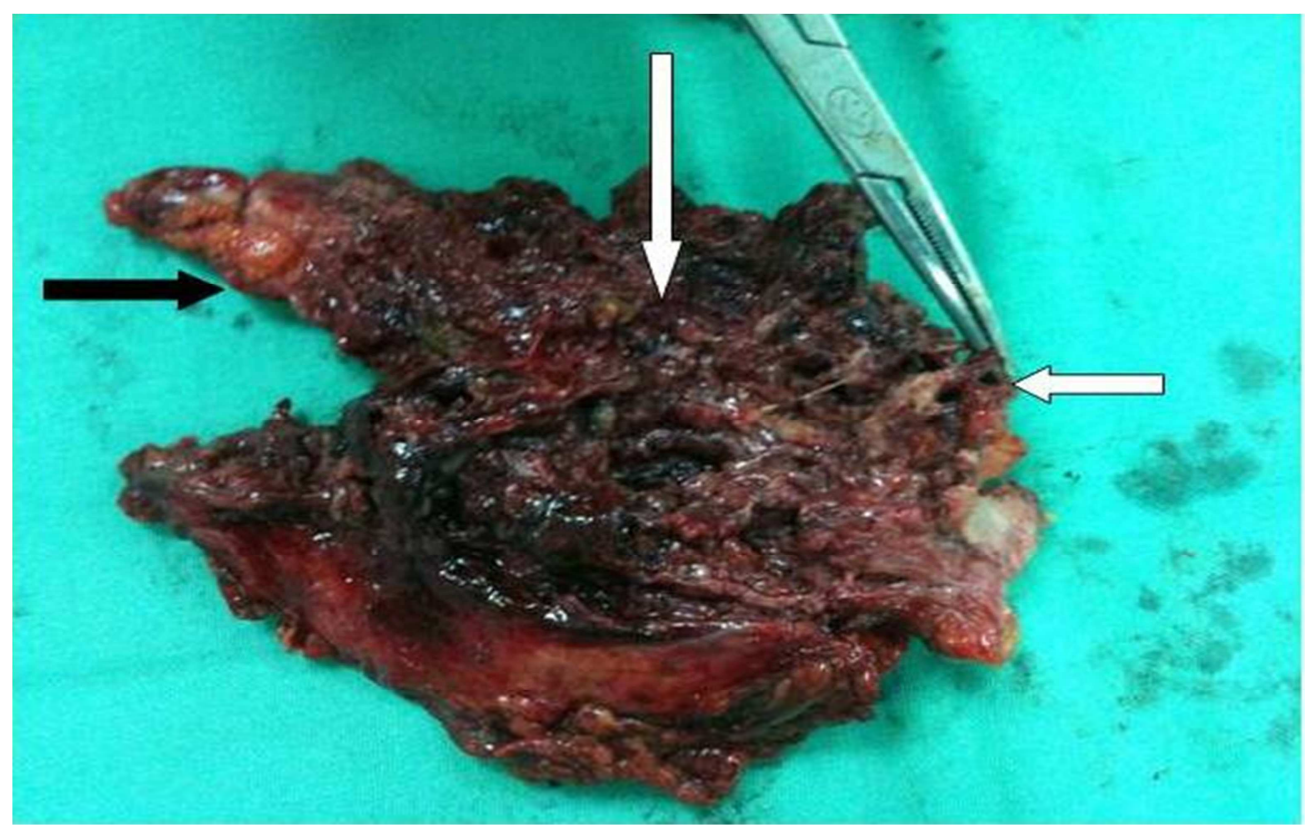

Figure 4. View of Resected Urachal Cyst (Long White Arrow), Enterocutaneous Fistula Tract (Short White Arrow) and Perforated Meckel's Diverticulum (Black Arrow) 
A histopathological examination of the specimen revealed a focal ulcerated area in the small intestinal mucosa with intense inflammation, gastric ectopic tissue in MD, mucosal ulceration adjacent to the diverticulum, submucosal edema in small intestinal tissue, acute inflammatory infiltration in serosa and fibroadipose tissue in the UC.

\section{Discussion}

Meckel's diverticulum was first described by Fabricus Hildanus in 1598, but it derives its name from Johann Friedrich Meckel, who well explained its anatomy and embryologic origins in $1809(9,16)$. Meckel's diverticulum is a remnant of omphalomesenteric or vitelline duct and it connects the growing embryo's midgut to the yolk sac during early development (17). Normally, the allantois and upper portion of the bladder become obliterated during the sixth to eighth weeks of gestation and are postnatally represented as a thick fibrous band (ie. urachus) that connects umbilicus and bladder $(1,15,18)$. Failure of the omphalomesenteric duct involution, either partial or complete, can result in various abnormalities, including patent omphalomesenteric duct, omphalomesenteric fistulas, enterocysts and MD both with and without fibrous bands connecting them to the umbilicus (1, 19, 20).

The position of MD according to the small intestine is variable, but it typically arises from the anti-mesenteric surface of ileum within 90-100 cm distance from ileocecal valve in $90 \%$ of cases and MD is a true diverticulum that contains all layers of the intestinal wall (21-24). MD has a separate mesentery and its vessels arise from the ileal vascular network. Our patient had MD arising from the mesenteric side of the ileum and was located $80 \mathrm{~cm}$ proximal to the ileocecal valve (Figure 3).

The lifetime incidence of $\mathrm{MD}$ to be presented with symptoms is $4-6.4 \%$ (8, 25). A comprehensive study made on patients with symptomatic MD displayed that $40 \%$ of them show symptoms before 10 years old (26). Most MD's are found incidentally by autopsy, laparotomy or barium studies. MD complications most often result from ectopic tissue or bands, either umbilical or mesodiverticular (27, 28). Clinical manifestations of MD are various such as abdominal pain, vomiting, tarry or currant-jelly stool and palpable mass.

The complications of MD include ulceration, gastrointestinal hemorrhage, intussusception, intestinal obstruction, volvulus, diverticulitis, perforation, acute intraabdominal inflammation, Littre hernia (Meckel's diverticulum within an inguinal hernia sac) and, although very rarely, vesicodiverticular fistula and tumors (carcinoid tumor, sarcoma, stromal tumor, carcinoma, adenocarcinoma and intraductal papillary mucinous adenoma of the pancreatic tissue), $(5,18,28,29)$. The usual complications of MD in adults are obstruction (14-53\%) secondary to intussuception or volvulus, ulceration (54\%), diverticulitis and perforation. It is a common complication that fistula formations are found between other hollow organs among colonic diverticular diseases; however, the fistula with $\mathrm{MD}$ is an extremely rare complication $(29,30)$. The literature concerning fistula related to MD included an enterocolonic fistula, a vesicodiverticular fistula, ileorectal fistula and MD with fistula-in-ano (29-34). The fistula formation is related to the inflammation in MD and progression to the adjacent visceral organ (29). Although the clinical, pathological and radiological features of the complications of MD are well known, the diagnosis is difficult to establish preoperatively.

Complications arising from MD usually occur at young age and the reason of the symptoms is generally an ectopic tissue present in the diverticulum. Heterotopic gastric and pancreatic mucosa are frequently found histologically within the diverticula patients with symptoms. Up to sixty percent of MD contain heterotopic mucosa and of these more than $60 \%$ contain gastric mucosa. Other heterotopic tissues include pancreatic acini, Brunner's glands, pancreatic islets, colonic mucosa, 
endometriosis and hepatobiliary tissue (35, 36).

Urachus is a normal embryonic remnant of the primitive bladder dome. It generally exists as a fibrous cord extending from the dome of the bladder to the umbilicus $(37,38)$. Normally the lumen obliterates and becomes a fibrous tract during embryologic development. An urachal anomaly occurs when obliteration is incomplete with left persistent lumen. This can occur along the whole tract, resulting in a patent urachus; or it can occur along a part of the tract creating an urachal sinus, cyst or vesicourachal diverticulum $(37,39)$. Data combined from large series shows the most common type of urachal anomaly to be cysts $(45 \%)$, followed by sinuses (37\%) and patent urachus (16\%), (40). Screening studies have shown that some urachal anomalies are asymptomatic; however, the majority are symptomatic and present clinically with leakage, signs of infection or a palpable mass.

Urachal cyst formation can be observed in various clinical presentations. These are calcification of the cyst wall, acute abdominal pain secondary to hemorrhage into the cyst, intraabdominal rupture leading to peritonitis, calculus formation within the cyst, urachal mass secondary to infected suture granuloma or appendiceal abscess, or spontaneous rupture without infection (41-46). Most UC's are generally infected and the responsible microorganism is usually Staphylococcus aureus (47). Furthermore, infected UC can be radiologically mistaken for MD (48). But formation of enterocutaneous fistula from umbilicus after the penetration and perforation of MD into UC have not been reported yet.

The preoperative diagnosis of MD is difficult to establish. Less than $10 \%$ of it is diagnosed before surgery (49). Abdominal ultrasonography and CT are very important in the diagnosis and differential diagnosis of UC. But these can sometimes be misleading as were in our case and can spare the definite diagnosis. Concerning abdominal CT scans appendicitis, Crohn's disease, ileal diverticulitis and infected urachal duct cysts must be thinked of in the radiological differential diagnosis of $\mathrm{MD}$ $(16,50)$. Radiological findings for our patient (ie. abdominal CT) were consistent with complicated Crohn's disease, intrabdominal mass and enterocutaneous fistula formation with the first more likely to be (Figure 1-2).

\section{Conclusion}

In conclusion, the diagnosis and treatment of the coexisting MD and UC is not easy because of the rareness of these diseases and the atypical symptoms at presentation. Because of the variable clinical presentation, uniform guidelines for evaluation and treatment are lacking. The umbilical enterocutaneous fistula formation may result from a variety of congenital and acquired pathologies, some of which may be life threatening. The knowledge of developmental anatomy of the umbilicus provides a basis for formulating an approach to evaluation, diagnosis and treatment of these conditions. Laparotomy can be useful for making an accurate and prompt diagnosis of MD and UC. Surgical treatment involves excision or radical exstirpation to prevent early and late complications. General surgeons should be aware of this rare possibility to avoid misdiagnosis and life threatening complications.

\section{Conflict of Interest}

No conflict of interest was declared by the authors.

\section{References}

1. Ozel, L. Z., Talu, M., User Y. et al. (2005). "Coexistence of a Meckel's Diverticulum and a Urachal Remnant," Clinical Anatomy, 18: 609-12.

2. Buchvald, F. F. \& Paerregaard, A. (2000). "Meckel's Diverticulum. From Embryology to Therapy," Ugeskrift for Laeger, 162: 914-18.

3. Digiacomo, J. C. \& Cottone, F. J. (1993). "Surgical Treatment of Meckel's 
Diverticulum," Southern Medical Journal, 86: 671-5.

4. Park, J. J., Wolff, B. J., Tollefson, M. K. et al. (2005). "Meckel's Diverticulum: The Mayo Clinic Experience with 1476 Patients (1950-2002)," Annals of Surgery, 241:529-33.

5. Sagar, J., Kumar, V. \& Shah, D. (2006). "Meckel's Diverticulum: A Systematic Review," Journal of the Royal Society of Medicine, 99: 501-5.

6. Turgeon, D. K. \& Barnett, J. L. (1990). "Meckel's Diverticulum," American Journal of Gastroenterology, 85: 77781.

7. Cullen, J. J. \& Kelly, K. A. (1996). "Current Management of Meckel's Diverticulum," Advances in Surgery, 29: 207-14.

8. Lüdtke, F. E., Mende, V., Kohler, H. \& Lepsien, G. (1989). "Incidence and Frequency or Complications and Management of Meckel's Diverticulum," Surgery, Gynecology \& Obstetrics, 169: 537-42.

9. Jain, A., Chauhan, M. S., Pandit, A. G., Kumar, R. \& Sharma, A. (2012). "Promising Role of Single Photon Emission Computed Tomography/Computed Tomography in Meckel's Scan," Indian Journal of Nuclear Medicine, 27(3): 196-8.

10. Yahchouchy, E. K., Marano, A. F., Etienne, J. C. \& Fingerhut, A. L. (2001). "Meckel's Diverticulum," Journal of the American College of Surgeons, 192(5): 658-62.

11. Mifsud, M. \& Ellul, E. (2011). "Meckel's Diverticulum in a Strangulated Femoral Hernia. Case Report and Review of Literature," Annali Italiani di Chirurgia, 82(4): 305-7.

12. Kusumato, H., Yoshida, M., Takahashi, I., Anai, H. \& Sugimachi, H. (1992). "Complications and Diagnosis of Meckel's Diverticulum in 776 Patients,"
The American Journal of Surgery, 164: 382-4.

13. Soltero, M. J. \& Bill, A. H. (1976). "The Natural History of Meckel's Diverticulum and Its Relation to Incidental Removal, A Study of 202 Cases of Diseasedmeckel's Diverticulum Found in King County, Washington, Over a Fifteen Year Period," The American Journal of Surgery, 132:168-73.

14. Leijonmarck, C. E. \& Bonman-Sandelin, K., Frisell, J. \& Raf, L. (1986). "Meckel's Diverticulum in the Adult," British Journal of Surgery 73: 146-9.

15. De La Taille, A., Cuvillier, X., Donnaint, A., Biserte, J. \& Mazeman, E. (1994). “A Case of Association of Cyst of the Urachus and Meckel's Diverticulum," Journal D'urologie, 100(5): 267-8.

16. Novoa, R. A. \& Shaffer, K. (2008). "Meckel's Diverticulitis Presenting with Abdominal Pain and Angin," Radiology Case Reports, 3: 166.

17. Menezes, M., Tareen, F., Saeed, A. et al. (2008). "Symptomatic Meckel's Diverticulum in Children: A 16-Year Review," Pediatric Surgery International, 24: 575-77.

18. Odze, Robert, D., Goldblum, John R. \& Crawford, James M. (2004). "Surgical Pathology of the GI Tract, Liver, Biliary Tract, and Pancreas," Elsevier, Philadelphia. 177-79.

19. Ioannidis, O., Paraskevas, G., Kakoutis, E., Kotronis, A., Papadimitriou, N., Chatzopoulos, S. \& Makrantonakis A. (2012). "Coexistence of Multiple Omphalomesenteric Duct Anomalies," Journal of the College of Physicians and Surgeons Pakistan, 22(8): 524-6.

20. Ameh, E. A., Mshelbwala, P. M., Dauda, M. M., Sabiu, L. \& Nmadu, P. T. (2005). "Symptomatic Vitelline Duct Anomalies in Children," South African Journal of Surgery, 43(3): 84-5. 
21. Yahchouchy, E. K., Marano, A. F., Etienne, J. C. \& Fingerhut, A .L. (2001.) "Meckel's Diverticulum," Journal of the American College of Surgeons, 192: 658-62.

22. Mackey, W. C. \& Dineen, P. (1983) "A Fifty Year Experience with Meckel's Diverticulum," Surgery, Gynecology \& Obstetrics, 156: 56-64.

23. Digiacoma, J. C. \& Cottone, F. J. (1993). "Surgical Treatment of Meckel's Diverticulum," Southern Medical Journal, 86: 671-5.

24. Williams, R. S. (1981). "Management of Meckel's Diverticulum," British Journal of Surgery, 68: 477-80.

25. Leijonmarck, C. E., Bonman-Sandelin, K., Frisell, J. et al. (1986). "Meckel's Diverticulum in the Adult," British Journal of Surgery, 73: 146-9.

26. Yamaguchi, M., Takeuchi, S. \& Awazu, S. (1978). "Meckel's Diverticulum. Investigation of 600 Patients in the Patients in the Japanese Literature," The American Journal of Surgery. 136: 247-9.

27. Ueno, T., Hashimoto, H., Yokoyama, H., Ito, M., Kouda, K. \& Kanamaru, H. (2003). "Urachal Anomalies: Ultrasonagraphy and Management," Journal of Pediatric Surgery, 38: 12037.

28. Dumper, J., Mackenzie, S., Mitchell, P., Sutherland, F., Quan, M. L. \& Mew, D. (2006). "Complications of Meckel's Diverticula in Adults," Canadian Journal of Surgery, 49(5): 353-7.

29. Yang, P.- F. et al. (2012). "A Rare Complication of Meckel's Diverticulum: A Fistula between Meckel's Diverticulum and the Appendix," Asian Journal of Surgery, 35: 163-5.

30. St-Vil, D., Brandt, M. L., Panic, S. et al. (1991). "Meckel's Diverticulum in Children: A 20 Year Review," Journal of Pediatric Surgery, 26: 1289-92.
31. Reimer, E. \& Struckmann, J. (1988). "An Enterocolic Fistula Originating from a Meckel's Diverticulum," Ugeskrift for laeger, 150: 1365-6.

32. Dearden, C. \& Humphreys, W. (1983). "Meckel's Diverticulum: A Vesicodiverticular Fistula," The Ulster Medical Journal, 52: 73-4.

33. Watt, N. A., Scott, I. H. \& Williams, M. P. (1985). "Unusual Presentation of Meckel's Diverticulum," Journal of the Royal Society of Medicine, 78: 258-60.

34. McKay, I. \& Calder, J. (1973). "Meckel's Diverticulum Presenting as Fistula-inano," British Medical Journal, 4: 31-2.

35. Yamaguchi, M., Takeuchi, S. \& Awazu, S. (1978). "Meckel's Diverticulum Investigation of 600 Patients in the Japanese Literature," The American Journal of Surgery, 136: 247-9.

36. Weinstein, E. C., Cain, J. C. \& Remine, W. H. (1962). "Meckel's Diverticulum: 55 Years of Clinical and Surgical Experience," JAMA, 182: 131-3.

37. Cilento, B. G., Bauer, S. B., Retik, A. B., Peters, C. A. \& Atala, A. (1998). "Urachal Anomalies: Defining the Best Diagnostic Modality," Urology, 52(1): 120-2.

38. McCrystal, D. J., Ewing, M. J. \& Lambrianides, A. L. (2001). "Acquired Urachal Pathology: Presentation of Five Cases and a Review of the Literature," ANZ Journal of Surgery, 71(12): 774-6.

39. Blichert-Toft, M. \& Nielson, O. V. (1971). 'Congenital Patent Urachus and Acquired Variants,' Acta Clin Scand, 137: 807-14.

40. Yiee, J. H. et al. (2007). "A Diagnostic Algorithm for Urachal Anomalies," Journal of Pediatric Urology, 3: 500-4.

41. Leyson, J. F. J. (1984). "Calcified Urachal Cyst," British Journal of Urology, 56: 438. 
42. Diehl, K. (1991). "A Rare Case of Urachal Calculus," British Journal of Urology, 67: 327-8.

43. Davidson, B. R., Brown, N. J. \& Neoptolemos, J. P. (1987). "Haemorrhage into a Urachal Cyst Presenting as a 'Acute Abdomen," Postgraduate Medical Journal, 63: 4934.

44. Agatstein, E. H. \& Stabile, B. E. (1984). "Peritonitis Due to Intraperitoneal Perforation of Infected Urachal Cysts," Archives of Surgery, 119: 1269-73.

45. Sawczuk, I. S. \& Brown, W. (1992). "Appendiceal Abscess Presenting as an Infected Urachal Cyst," New York State Journal of Medicine, 92: 365.

46. Katz, P. G., Crawford, J. P. \& Hackler, R. H. (1986). "Infected Suture Granuloma Simulating Mass of Urachal Origin: Case Report," Urology, 135: 782-3.
Recognition, and Management," Urology 40: 530-5.

48. Yu, J. S., Kim, K. W., Lee, H. J. et al. (2001). "Urachal Remnant Diseases: Spectrum of CT and US Findings," RadioGraphics, 21(2): 451-61.

49. Karatepe, O., Adas, G., Altiok, M. et al. (2009). "Meckel's Diverticulum Manifested by Subcutaneous Abscess," World Journal of Gastroenterology, 15(48): 6123-5.

50. Bennett, G. L., Birnbaum, B. A. \& Balthazar, E. J. (2004). "CT of Meckel's Diverticulitis in 11 Patients," American Journal of Roentgenology, 182(3): 6259.

47. Macneilly, A. E., Koleilat, N., Kiruluta, H. G. et al. (1992). "Urachal Abscesses: Protean Manifestations, Their 